\title{
DESENVOLVIMENTO E CARACTERIZAÇÃO DE SORVETE DE AÇAÍ, GUARANÁ E BANANA ENRIQUECIDO COM FITOESTEROL
}

\section{CHARACTERIZATION OF ICE CREAM ACAI, GUARANÁ BANANA AND ADDED PHYTOSTEROL}

\begin{abstract}
Marina Leopoldina Lamounier ${ }^{1}$; Fernanda Araújo Silva ${ }^{2}$; Clélia Cristina de Almeida ${ }^{3}$; Rômulo Leal da Silva ${ }^{4}$ 1,2,3,4 Instituto Federal de Minas Gerais campus Bambuí - IFMG -Bambuí - Brasil marina.lamounier@ifmg.edu.br
\end{abstract}

\section{Resumo}

Tendência atual vêm sendo dada a alimentos enriquecidos com fitosteróis, pois há indícios que os mesmos estão envolvidos na redução de colesterol, dos níveis plasmáticos e diminuição da incidência de aterosclerose. Entretanto, mais pesquisas devem ser realizadas pois ainda não há um consenso sobre os efeitos adversos e novas formas de processamento para isolamento de fitoesteróis devem ser descobertas. Este trabalho teve por objetivo avaliar as propriedades físicosquímicas, microbiológicas e sensoriais de sorvete saborizado com polpa de açaí, guaraná e banana enriquecido com fitoesterol. Realizou-se avaliação da composição química como pH, acidez total titulável, sólidos solúveis $\left({ }^{\circ}\right.$ Brix) e o teor de overrun. Foi realizada também a aceitação e intenção de compra (por meio de escala hedônica de 9 pontos para aceitação e 5 pontos para intenção de compra), bem como as características microbiológicas (coliformes totais e $45^{\circ} \mathrm{C}$ e estafilococos coagulase +). Como resultado o sorvete se mostrou prominssor pois apresentou significativa aceitação sensorial e valores físico-químicos atrativos, estando também dentro dos padrões sanitários e desta forma, pode se tornar uma opção interessante tanto para a indústria como para a saúde do consumidor.

Palavras-chave: sorvete funcionais, redução do colesterol, análise.

\section{Introdução}

Desde início dos anos 50 estudam-se os fitoesteróis como potenciais inibidores da absorção de colesterol (BEST et al., 1954), contudo, só em 1995 foram adicionados a alimentos (CLIFTON, 2009). Esses, compostos ocorrem naturalmente em plantas e são estruturalmente e funcionalmente semelhante ao colesterol.

No intestino, os fitoesteróis têm a capacidade de bloquear a absorção e diminuir em partes a recirculação endógena do colesterol. Em quantidades adequadas, os fitoesteróis podem deslocar até $50 \%$ do colesterol que seria absorvido pelas micelas (moléculas pequenas o suficiente para 
passar por difusão através das microvilosidades intestinais e permitirem assim a absorção de lipídeos através da superfície das células intestinais) (BERNE e LEVY, 2000). Apesar de toda afinidade e semelhança estrutural, o fitoesterol não é absorvido pelo organismo. Após se ligar às micelas e impedir em partes a absorção do colesterol, ambos compostos não absorvidos são excretados pelas fezes (MATSUOKA et al, 2010).

Alguns estudos mostram que a eficácia dos fitoesteróis sob a redução de níveis de colesterol não é a mesma para os diferentes alimentos fortificados, pois em alimentos mais gordurosos, provocam maiores diminuições nos níveis de colesterol LDL quando comparado a outros produtos alimentares, como leite, pão e cereais enriquecidos com os mesmos (CLIFTON et al., 2004; EUSSEN et al., 2011).

Paralelamente à comprovação dos benefícios proporcionados pela ingestão do fitoesterol, observa-se o crescente interesse pela utilização de alimentos funcionais que são fontes de energia e que apresentam compostos bioativos capazes de reduzir doenças. O açaí é considerado um super alimento, pois possui em sua composição elevados teores de antioxidantes, compostos fenólicos, proteínas, fibras, lipídios, vitaminas (C, E, B1 e B2) e minerais (fósforo, ferro e cálcio). Entre seus benefícios, destacam-se os poderes de reposição energética, combate à fadiga (com consequente aumento do rendimento em exercícios físicos e fortalecimento muscular), auxílio na regulação da função intestinal, auxílio no combate ao envelhecimento, prevenção de certos tipos de câncer, combate aos radicais livres e combate e prevenção da anemia ferropriva (KUSKOSKI et al., 2002; MENEZES et al., 2008; SANTOS et al., 2008; SANTOS, 2008; PORTINHO et al., 2012).

Já o guaraná, apresenta grande interesse industrial e farmacêutico por ser considerado um alimento estimulante, que aumenta a resistência nos esforços mentais e musculares, diminuindo a fadiga motora e psíquica, além de tonificar o coração e apresentar propriedades diuréticas (NAZARÉ, 1998).

A banana constitui-se em fonte importante na alimentação humana pelo valor calorífico, energético e, principalmente, pelo conteúdo mineral e vitamínico que apresenta. Devido às suas características aromáticas, as bananas têm recebido considerável atenção dos pesquisadores, com mais de 350 compostos identificados. Os maiores constituintes são os ésteres amil e éster isoamil de ácidos butírico, propiônico e acético o que faz dela também uma fruta nutricionalmente completa favorecendo a sua incorporação em produtos alimentícios com consequente comercialização (LIMA et al., 2000).

Pensando no fato de que o sorvete é uma matriz gordurosa e susceptível à adição de fitoesterol, decidiu-se adicionar esta substância nessa matriz que também é amplamente aceita e conhecida. Além do mais, optou-se por saborizar este sorvete com frutas funcionais como o açaí, guaraná e banana que ganham espaço cada vez maior na mesa dos consumidores e desta forma, este 
sorvete desenvolvido pode se constituir em uma medida aliada na prevenção de algumas doenças. O interesse principal é fazer com que o sorvete tenha múltiplas funções, pois o consumidor moderno deseja alimentos que satisfaça e que ao mesmo tempo seja saudável.

Sendo assim, o objetivo deste trabalho foi verificar as características físico-químicas, microbiológicas e sensoriais de sorvete saborizado com açaí, guaraná e banana enriquecido com fitoesterol.

\section{MATERIAL E MÉTODOS}

\section{Instalação do experimento e preparação das amostras}

O desenvolvimento do sorvete foi conduzido na Unidade de Processamento de Frutos e Hortaliças do Instituto Federal de Educação, Ciência e Tecnologia - campus Bambuí (IFMG-BÍ).

Para a fabricação do sorvete foi utilizado os seguintes ingredientes: polpa de açaí, guaraná e banana; fitoesterol em pó; leite em pó integral; gordura láctea; liga neutra; glucose de milho e leite integral (Tabela 1).

A polpa de açaí, guaraná e banana foi gentilmente cedida pela empresa Vivare®, o fitoesterol pela empresa Tovani ${ }^{\circledR}$ e os demais ingredientes foram adquiridos no comércio local.

Tabela 1 - Formulação do sorvete de açaí, guaraná e banana enriquecido com fitoesterol

\begin{tabular}{cc}
\hline Ingredientes & Quantidade (\%) \\
\hline Polpa de açaí, guaraná e banana & 20 \\
Leite integral- 3,5\% de gordura & 7 \\
Creme de leite & 5 \\
Leite em pó & 5 \\
Glucose de milho & 10 \\
Sacarose & 12 \\
Liga neutra & 1 \\
Fitoesterol & 1,5 \\
\hline
\end{tabular}

\section{Processo de obtenção do sorvete}

Na etapa inicial para a fabricação do sorvete foi produzida a mistura base através da junção de todos os ingredientes em pó (incluindo o fitoesterol). O leite integral foi adicionado para a produção da calda que foi homogeneizada em liquidificador industrial. Em seguida, a calda foi pasteurizada por $63{ }^{\circ} \mathrm{C}$ por $30 \mathrm{~min}$ e depois resfriadas até $20^{\circ} \mathrm{C}$. A polpa de açaí, guaraná e banana, que já veio da empresa esterilizada, foi incorporada à calda do sorvete _ e esta mistura foi maturada em geladeira por $12 \mathrm{~h}$ a $8{ }^{\circ} \mathrm{C}$ para que houvesse a incorporação dos ingredientes. Em seguida, esta mistura foi submetida ao processo de batimento, dando origem ao sorvete. $\mathrm{O}$ endurecimento foi realizado em freezer convencional com temperatura entre $-18^{\circ}$ a $-20{ }^{\circ} \mathrm{C}$. Uma vez endurecido, o 
produto foi armazenado em potes previamente esterilizados, identificados com a descrição do conteúdo.

\section{Análise físico-química dos sorvetes}

Análise de pH, Sólidos Solúveis Totais (SST), Acidez Titulável (ATT) e Overrun

A determinação do $\mathrm{pH}$ foi feita mediante o método eletrométrico, utilizando-se um pHmetro digital (IAL, 2005). O teor de sólidos solúveis totais do sorvete foi obtido por leitura direta em refratômetro (marca Atago n.1 0 32 ${ }^{\circ}$ Brix) e os valores expressos em ${ }^{\circ}$ Brix (PRADO, 2009). A acidez titulável foi determinada de acordo com a metodologia descrita por Pregnolato e Pregnolato (1985). O overrun foi determinado de acordo com o método descrito por Whelan et al. (2008). Volumes iguais $(50 \mathrm{~mL})$ de sorvete foram pesados e o overrun foi calculado conforme a Equação 1:

Overrun $(\%)=$ peso da mistura base peso do sorvete $\times 100$

\section{Peso do sorvete}

\section{Características microbiológicas do sorvete}

As análises microbiológicas foram realizadas em triplicatas nas amostras de sorvete de acordo com as exigências da Agência Nacional de Vigilância Sanitária (ANVISA). Foi feita a contagem de coliformes a $45^{\circ} \mathrm{C}$ e totais e presença de estafilococos coagulase + (DOWNES e ITO, 2001).

\section{Teste de aceitação e intenção de compra dos sorvetes}

Para a avaliação sensorial do sorvete foram utilizados 50 provadores não treinados. $\mathrm{O}$ teste foi realizado em cabines individuais, durante o período matutino (09:00 às 11:00). Foi aplicado o teste de aceitabilidade, utilizando escala hedônica estruturada de nove pontos (ABNT, 1998), variando de "1" (desgostei extremamente) a "9" (gostei extremamente). Os atributos avaliados foram aroma, sabor, textura, aparência e aspecto global. Os provadores também foram questionados quanto à intenção de compra do produto e as notas variaram de "1" (certamente não compraria) a "5"(certamente compraria).

As amostras foram apresentadas sob iluminação ambiente e oferecida a cada um dos 50 provadores. $\mathrm{O}$ sorvete foi servido em temperatura de $-10{ }^{\circ} \mathrm{C}$ e $20 \mathrm{ml}$ foram colocados em copos descartáveis brancos. 


\section{RESULTADOS E DISCUSSÃO}

Análise de $\mathrm{pH},{ }^{\circ}$ Brix, Acidez e Overrun

Os resultados médios obtidos nas determinações físicas e químicas do sorvete estão apresentados na Tabela 2.

Tabela 2 - Valores de $\mathrm{pH},{ }^{\circ}$ Brix $(\mathrm{SST})^{(1)}$, Acidez e Overrun do Sorvete

\begin{tabular}{llll}
\hline $\mathrm{pH}$ & SST & Acidez $\left(\right.$ ATT) ${ }^{(2)}$ & Overrun \\
\hline 6,33 & 22,3 & 2,32 & 86,93 \\
\hline em $^{\circ}$ Brix; ${ }^{(2)}$ Expresso em \% de ácido cítrico & &
\end{tabular}

${ }^{(1)}$ Expresso em ${ }^{\circ} \mathrm{Brix} ;{ }^{(2)}$ Expresso em \% de ácido cítrico

$\mathrm{O}$ pH do sorvete analisado apresentou resultado de 6,33 mostrando estar próximo da neutralidade e a elevação deste pH é justificado pela adição do leite e outras fontes de sólidos solúveis acrescentados. Além do mais, o resultado encontrado está de acordo com outras pesquisas (AKALIN e ERISIR, 2008; CRISCIO et al., 2010; PEREIRA et al., 2011).

Quanto aos parâmetros de Sólidos Solúveis Totais (SST), expressos em ${ }^{\circ}$ Brix, que representa os compostos solúveis em água, a formulação apresentou resultado de $22,3^{\circ} \mathrm{Brix}$ mostrando que a quantidade de açúcar adicionada foi elevada, e desta forma, se apresenta como fonte de SST expressando coerência com a formulação elaborada.

A acidez total titulável de sorvetes é um parâmetro influenciado pela fruta utilizada e tendo em vista que a polpa de açaí, banana e guaraná possuem elevada acidez, este fator influenciou diretamente na acidez do sorvete que foi de 2,32.

Já o resultado da análise de overrun revelou que o sorvete apresentou uma eficaz incorporação de ar, melhorando desta forma a estrutura e cremosidade do produto. Este resultado também vem de encontro à elevação do rendimento do produto, fato justificado pelo aumento de ar. De acordo com Sofjan e Hartel (2004), o ar em sorvetes fornece uma textura mais suave e influencia as propriedades físicas de derretimento.

\section{Análise Sensorial}

Sobre os cinco atributos avaliados (aroma, sabor, textura, aparência, aspecto global e intenção de compra) (Tabela 3), todos os atributos receberam notas acima de 8 , demonstrando que os provadores gostaram muito do produto desenvolvido. Entre todos os quesitos avaliados, o sabor foi o que mais se destacou apresentando nota de 8,33 . Vale destacar, que se um produto não apresentar um sabor agradável, dificilmente o mesmo se firmará no mercado, mesmo que este apresente funções específicas na saúde. O segundo atributo melhor votado foi a aparência, recebendo nota de 8,26. A primeira impressão que se tem de um alimento é geralmente visual, 
sendo que, a aparência é um dos aspectos considerados fundamentais na qualidade e aceitação do produto.

Tabela 3 - Atributos sensoriais do sorvete

\begin{tabular}{|c|c|c|c|c|c|}
\hline Aroma & Sabor & Textura & Aparência & $\begin{array}{l}\text { Aspecto } \\
\text { Global }\end{array}$ & Intenção de compra \\
\hline 8,11 & 8,33 & 8,25 & 8,26 & 8,18 & 4,5 \\
\hline
\end{tabular}

Os provadores não relataram na ficha de avaliação nenhuma observação quanto às características sensoriais da formulação e a percepção da presença de fitoesterol. Provavelmente a adição deste ingrediente não foi notada e este fato impulsiona ainda mais o uso deste ingrediente.

Finalmente, quando questionados sobre a intenção de compra do produto, observa-se que o produto em questão apresentou nota elevada $(4,5)$ representando que os consumidores aceitaram o produto e provavelmente o comprariam.

Pode ser sugerido então, que o sorvete formulado no presente trabalho, oferece boas perspectivas de consumo e, portanto, apresenta potencial para ser produzidos em escala comercial.

\section{Características Microbiológicas}

Conforme apresentado na Tabela 4, os resultados de coliformes totais e a $45{ }^{\circ} \mathrm{C}$ e Estafilococos coagulase positiva encontrados para o sorvete, situam-se dentro dos limites propostos pela legislação brasileira vigente. Tais resultados são satisfatórios, posto que atendem aos requisitos mínimos de qualidade para o consumo humano. Desta forma, os sorvetes estão em conformidade com os padrões estabelecidos pela ANVISA (BRASIL, 2001).

Tabela 4 - Resultados da análise microbiológica do sorvete

\begin{tabular}{lll}
\hline Coliformes totais & Coliformes a $\mathbf{4 5}^{\mathbf{0}}$ & Estafilococos \\
\hline $240 \mathrm{NMP} / \mathrm{g}$ & $9 \mathrm{NMP} / \mathrm{g}$ & $1,0 \times 10^{1} \mathrm{UFC} / \mathrm{ml}$ \\
\hline
\end{tabular}

Este órgão estabelece como tolerância de microrganismos para preparo de gelados comestíveis o valor máximo para contagem de coliformes a $45{ }^{\circ} \mathrm{C} / \mathrm{g}$ de $10 \mathrm{NMP} / \mathrm{g}$. Em relação aos gelados comestíveis elaborados com leite, o valor máximo permitido de contagem de coliformes a $45^{\circ} \mathrm{C} / \mathrm{g}$ é de 5,0x10 UFC/g e contagem de estafilococos coagulase positiva de 5,0 x $10^{2} \mathrm{UFC} / \mathrm{g}$. Sabe-se que coliformes são bons indicadores das condições sanitárias dos alimentos, assim 100\% das amostras examinadas estão em condições sanitárias satisfatórias e adequadas para uma possível comercialização. 


\title{
4 CONCLUSÃO
}

O sorvete analisado apresentou significativas características sensoriais com graus de aceitação satisfatórios para os atributos aroma, sabor, textura, aparência, aspecto global e intenção de compra, ressaltando sua possível viabilidade comercial. Sobre as características microbiológicas, o sorvete está de acordo com os padrões da legislação vigente. No diz que diz respeito às características físico-químicas, os quesitos brix, $\mathrm{pH}$, acidez e overrun também apresentaram resultados que se destacaram favorecendo a constituição do sorvete. Além disso, a pesquisa e comercialização de produtos à base ingredientes saudáveis colaboram com um aproveitamento funcional no qual está a prevenção de diversas doenças. Entretanto, são necessárias novas pesquisas para testar e comprovar a redução de problemas de saúde (inclusive coronários) através do consumo deste sorvete.

\begin{abstract}
Current trends have been given the phytosterol -enriched foods because the evidence that they are involved in reducing cholesterol plasma levels and decreased incidence of atherosclerosis. However, more research should be done because there is no consensus on the adverse effects and new new ways of processing for isolation of phytosterols should be discovered. This study aimed to evaluate the physical, chemical, microbiological and sensory properties of ice cream flavored with acai pulp, guarana and enriched with phytosterol banana. We conducted evaluation of the chemical composition and $\mathrm{pH}$, titratable acidity, soluble solids $\left({ }^{\circ}\right.$ Brix $)$ and content overrun. Acceptance and purchase intent ( by hedonic scale of 9 points to 5 points for acceptance and purchase intent) was also performed, as well as microbiological (total coliforms and $45^{\circ} \mathrm{C}$ and coagulase + ). As a result the ice cream proved prominssor it showed significant sensory acceptance and attractive physicochemical values and are also within the health standards and thus can become an interesting option for both industry and for consumer health.
\end{abstract}

Key-words: functional ice cream; cholesterol reduction; analysis.

\section{REFERÊNCIAS}

AKALIN, A.S.; ERISIR, D. Effects of inulin and oligofructose on the rheological characteristics and probiotic culture survival in low-fat probiotic ice cream. JFSM: Food Microbiology and Safety, v. 73, n. 4, p. 184-188, 2008. http://dx.doi.org/10.1111/j.1750-3841.2008.00728.x

AKESON, W. R.; STAHMANN, M. A. A pepsin pancreatin digest index of protein quality evaluation. Journal of Nutrition, v. 83, p. 257-261, 1964.

ANVISA. Ministério da Saúde. Resolução RDC no 12, de 02 de janeiro de 2001 da Agência Nacional de Vigilância Sanitária (ANVISA) do Ministério da Saúde. Aprova o Regulamento Técnico sobre Padrões Microbiológicos para Alimentos. Diário Oficial [da] República Federativa do Brasil, Brasília, 10 de janeiro de 2001, Seção 1, p. 45-53.

AOAC. Association of Official Analytical Chemists. Official methods of analysis.16 ed. AOAC: Washington, D.C., 1995.

ASSOCIAÇÃO BRASILEIRA DE NORMAS TÉCNICAS. NBR 14141: escalas utilizadas em análise sensorial de alimentos e bebidas. Rio de Janeiro, 1998. 3 p. 
AWAD, A. M.; JAGER, A.; WESTING, L.M. Flavonoid and chlorogenic acid levels in apple fruit: characterization of variation. Scientia Horticulturae, v. 83, p. 249-263, 2000. http://dx.doi.org/10.1016/S0304-4238(99)00124-7

BERNE, R. M.; LEVY, M. N. Principles of Physiology. 3 ed. United States: Mosby; 2000.

BEST, M. M.; DUNCAN, C. H.; LOON, E. J. V.; WATHEN, J. D. Lowering of Serum Cholesterol by the Administration of a Plant Sterol. Circulation. 1954; v. 10, p. 201-06. http://dx.doi.org/10.1161/01.CIR.10.2.201

BUCIC-KOJIC, A.; PLANINIC, M.; SRECKO, T.; BILIC, M.; VELIC, D. Study of solid-liquid extraction kinetics of total polyphenols from grape seeds. Journal of Food Engineering, v. 81, p. 236-242, 2007. http://dx.doi.org/10.1016/j.jfoodeng.2006.10.027

CLIFTON P. Lowering cholesterol: A review on the role of plant sterols. Australian Family Physician. 2009; 38:218-21

CRISCIO, D. T.; FRATIANNI, R. A.; MIGNOGNA, L.; CINQUANTA, R.; COPPOLA, E.; SORRENTINO, G. Production of functional probiotic, prebiotic, and symbiotic ice creams. Journal of Dairy Science, v. 93, p. 4555-4564, 2010. http://dx.doi.org/10.3168/jds.2010-335

DESHPANDE, S. S.; CHERYAN, M. Determination of phenolic compounds of dry beans using vanilin, redox and precipitation assays. Journal of Food Science, v. 52, n. 2, p. 332-334, 1987. http://dx.doi.org/10.1111/j.13652621.1987.tb06606.x

DOWNES, F.P.; ITO, K. Compendium of methods for the microbiological examination of foods. 4 ed. Washington: American Public Health Association, 2001. 676 p.

DUGASANI, S., PICHIKA, M. R.; NADARAJAH, V. D.; BALIJEPALLI, M. K.; TANDRA, S.; KORLAKUNTA, J. N. Comparative antioxidant and anti-inflammatory effects of [6]-gingerol, [8]-gingerol, [10]-gingerol and [6]-shogaol. Journal of Ethnopharmacology, v. 127, p. 515-520, 2010. http://dx.doi.org/10.1016/j.jep.2009.10.004

EUSSEN, S. R.; JONG, N.; ROMPELBERG, C. J.; GARSSEN, J.; VERSCHUREN, W. M.; KLUNGEL, O. H. Dosedependent cholesterol-lowering effects of phytosterol/phytostanol-enriched margarine in statin users and statin non-users under free-living conditions. Public Health Nutrition. v. 14, n. 10, p. 1823-1832, 2011. http://dx.doi.org/10.1017/S1368980011000164

FAVA A. R. Atletas ingerem garapa para repor energia. Jornal da Unicamp. v. 1, n. 250,p. 8. 2004.

FERREIRA, D. F. Análises estatísticas por meio do SISVAR para Windows versão 4.0. In: REUNIÃO BRASILEIRA DA SOCIEDADE INTERNACIONAL DE BIOMETRIA, 45, 2000, São Carlos. Resumos... São Carlos: UFSCAR, 2000.p. 235.

HODGES, P. J.; KAM, P. C. A. The peri-operative implications of herbal medicines. Anaesthesia, 2002, 57, pages 889899. http://dx.doi.org/10.1046/j.1365-2044.2002.02781.x

IBGE. INSTITUTO BRASILEIRO DE GEOGRAFIA E ESTATÍSTICA. Estudo nacional da despesa familiar: Tabela de composição de alimentos. 5 ed. Rio de Janeiro: Varela, 1999. 137p.

INSTITUTO ADOLFO LUTZ. Normas analíticas do Instituto Adolfo Lutz: métodos químicos e físicos para análise de alimentos. Ed. Adolfo Lutz, 4 ed., São Paulo, 2005.

KUSKOSKI, E. M.; FETT, P.; ASUERO, A. G. Antocianos: un grupo de pigmentos naturales. Aislamiento, identificación y propriedades. Alimentaria, v.2 n.61, p.61-74, 2002.

LIMA, A.G. B.; NEBRA, S. Z; QUEIROZ, M. R. Aspectos científico e tecnológico da banana. Revista Brasileira de Produtos Agroindustriais, Campina Grande, v. 2, n. 1, p. 87-101, 200087.

MATSUOKA, K.; KAJIMOTO, E.; HORIUCHI, M.; HONDA, C.; ENDO, K. Competitive solubilization of cholesterol and six species of sterol/stanol in bile salt micelles. Chemistry and Physics Lipids. v. 163, n. 4-5, p. 397-402. 2010. http://dx.doi.org/10.1016/j.chemphyslip.2010.03.006

MENEZES, E. M. S.; TORRES, A. T.; SRUR, A. U. S. Valor nutricional da polpa de açaí (Euterpe oleracea Mart.) liofilizada. Acta Amazônica, v. 38, n. 2, p. 311-316, 2008. http://dx.doi.org/10.1590/S0044-59672008000200014 
NAZARÉ, R. F. R. de. Processamento de guaraná em pó solúvel. Belém: Embrapa-CPATU, 1998. 24 p.

NUNES, M.C.N.; BRECHT, J.K.; MORAIS, A.M.M.B.; SARGENT, S.A. Physical and chemical quality characteristics of strawberries after storage are reduced by a short delay to cooking. Postharvest Biology and Technology, v. 6, p. 1728, 1995. http://dx.doi.org/10.1016/0925-5214(94)00048-W

OliveirA, A. C. G.; NOGUEIRA, F. A G.; ZANÃO, C. F. P.; SOUZA C. W. O., SPOTO, M. H. F. Análise das Condições do Comércio de Caldo de Cana em Vias Públicas de Municípios Paulistas. Segurança Alimentar e Nutricional, v. 13, n. 2, p. 06-18, 2006

PEREIRA, G. G.; RESENDE, J. V.; ABREU, L. R.; GIAROLA, T. M. O.; PERRONE, I. T. Influence of the partial substitution of skim milk powder for soy extract on ice cream structure and quality. European Food Research and Technology, v. 232, p. 1093-1102, 2011. http://dx.doi.org/10.1007/s00217-011-1483-z

PORTINHO, J. A.; ZIMMERMANN, L. M.; BRUCK, M. R. Efeitos Benéficos do Açaí Beneficial effects of açaí. International Journal of Nutrology, v.5, n.1, p. 15-20, 2012.

PRADO, A. Composição fenólica e atividade antioxidante de frutas tropicais. 2009.107 p. Dissertação (Mestrado em Ciências de Alimentos) - Escola Superior de Agricultura “Luiz de Queiroz”, Universidade de São Paulo, Piracicaba, 2009.

PREGNOlatto, W.; PREgnolatto, N.P. Normas Analíticas do Instituto Adolfo Lutz: métodos químicos e físicos para análise de alimentos. São Paulo: Instituto Adolfo Lutz, 1985. v. 1, 533 p.

PRICE, M. L.; HAGERMAN, A. E.; BUTLER, L. G. Tannin content of cowpeas, chickpeas, pigeonpeas and mung beans. Journal Agricultural and Food Chemistry, v. 28, n. 2, p. 459- 461, 1980. http://dx.doi.org/10.1021/jf60228a047

RODRIGUES, E.; SCHWAN-ESTRADA, K. R. F.; STANGARLIN, J. R.; CRUZ, M. E. S.; FIORI-TUTIDA, A. C. G. Avaliação da atividade antifúngica de extratos de gengibre e eucalipto in vitro e em fibras de bananeira infectadas com Helminthosporium sp. Acta Science Agronomy, v. 28, n. 1, p. 123-127, 2006.

RODRIGUEZ-AMAYA, D. A. Guide to Carotenoids Analysis in Food. Washington: International Life Sciences Institute Press, 2001. 64p.

SANTOS, G. M. Correlação entre atividade antioxidante e compostos bioativos de polpas comerciais de açaí (Euterpe oleracea Mart). Archivos Latinoamericanos de Nutrición v. 58, n. 2, p. 187-192, 2008.

SANTOS, G. M.; MAIA. G. A.; SOUSA, P. H. M.; COSTA, J. M. C.; FIGUEIREDO, R. W.; PRADO, G. M. Correlação entre atividade antioxidante e compostos bioativos de polpas comerciais de açaí (Euterpe oleracea Mart). Archivos Latinoamericanos de Nutricion, v. 58, n. 2, p. 187-192, 2008.

SARRUGE, J. R.; HAAG, H. P. Análises químicas em plantas. Piracicaba: ESALQ, 1974. 56 p.

SOFJAN, R. P.; HARTEL, R. W. Effects of overrun on structural and physical characteristics of ice cream. International Dairy Journal, v. 14, n. 3, p. 255-262, 2004. http://dx.doi.org/10.1016/j.idairyj.2003.08.005

SOLER, M. P.; VEIGA, P.G. Sorvetes. Campinas: ITAL; CIAL, 2001. 68 p. (Especial, 1).

TERADA, M.; WATANABE, Y.; KUNITOMA, M.; HAYASHI, E. Differential rapid analysis ascorbic acid and ascorbic acid 2-sulfate by dinitrophenilhydrazine method. Annals of Biochemistry, v. 4, p. 604-8, 1979.

WHELAN, A.P.; VEGA, C.; KERRY, J.P.; GOFF, H.D. Physicochemical and sensory optimization of a low glycemic index ice cream formulation. International Journal of Food Science and Technology, v. 43, n. 9, p. 1520-1527, 2008. http://dx.doi.org/10.1111/j.1365-2621.2007.01502.x

Submetido em 05 fev. 2014, Aceito para publicação em 23 jun. 2014, Publicado em 28 dez. 2014. 